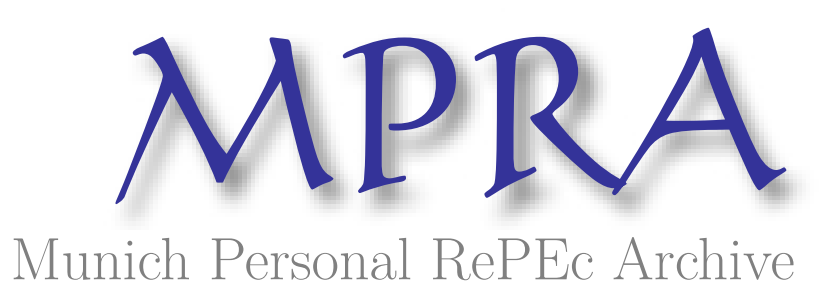

\title{
A Proof of the Invalidity of Proposition 15.12 in Acemoglu(2009)
}

Li, Defu

School of Economics and Management, Tongji University

29 November 2016

Online at https://mpra.ub.uni-muenchen.de/75329/

MPRA Paper No. 75329, posted 03 Dec 2016 07:15 UTC 


\title{
A Proof of the Invalidity of Proposition 15.12 in Acemoglu (2009)
}

\author{
Defu $\mathrm{Li}^{1}$
}

School of Economics and Management, Tongji University

Abstract: This note proves that unless the amount of scientists $S=\frac{s_{K}}{\eta_{L}}$, the proposition 15.12 in Acemoglu (2009) does not hold. Because this is an extremely restrictive requirement, it is not suitable as a proof of why the technological progress must be labor-augmenting on the BGP.

Key words: Acemoglu(2009), direction of technical change, Uzawa's steady-state theorem

Proposition 15.12 Consider the baseline model of directed technological change with the two factors corresponding to labor and capital. Suppose that the innovation possibilities frontier is given by the knowledge spillovers specification with extreme state dependence, that is, $\delta=1$, and that capital accumulates according to (15.45). Then there exists a unique BGP allocation in which there is only labor-augmenting technological change, the interest rate is constant and consumption and output grow at constant rates. (Acemoglu,2009, chapter 15,p521)

\section{Proof:}

(1) if $\mathbf{S}<\frac{s_{\mathrm{K}}}{\eta_{\mathrm{L}}}$, then even all scientists work on L-augmenting machines, but still, there is

$$
\frac{\dot{\mathrm{N}}_{\mathrm{L}}(\mathrm{t})}{\mathrm{N}_{\mathrm{L}}(\mathrm{t})}=\eta_{\mathrm{L}} \mathrm{S}_{\mathrm{L}}=\eta_{\mathrm{L}} \mathrm{S}<\mathrm{s}_{\mathrm{K}}=\frac{\dot{\mathrm{K}}(\mathrm{t})}{\mathrm{K}(\mathrm{t})}
$$

Owing to $\mathrm{S}_{\mathrm{K}}=0, \frac{\dot{\mathrm{N}}_{\mathrm{K}}(\mathrm{t})}{\mathrm{N}_{\mathrm{K}}(\mathrm{t})}=0$, then $\left(N_{L}(t) L\right) /\left(N_{K}(t) K(t)\right)$ will decrease forever. From equation (15.48) we can know that $r(t)$ cannot be constant. As a result, the BGP with purely labor-augmenting technical change cannot exist in this case.

(2) if $\mathbf{S}>\frac{s_{K}}{\eta_{\mathrm{L}}}$, we discuss this case in two different situations. One is that the scientists are full employed, the other is some scientists are unemployed.

(1) The scientists are full employed.

In this case, if all scientists work on L-augmenting machines, that is, $S_{L}=S, S_{K}=0$, then $\frac{\dot{\mathrm{N}}_{\mathrm{K}}(\mathrm{t})}{\mathrm{N}_{\mathrm{K}}(\mathrm{t})}=\eta_{\mathrm{K}} \mathrm{S}_{\mathrm{K}}=0$, but

$$
\frac{\dot{\mathrm{N}}_{\mathrm{L}}(\mathrm{t})}{\mathrm{N}_{\mathrm{L}}(\mathrm{t})}=\eta_{\mathrm{L}} \mathrm{S}>\mathrm{s}_{\mathrm{K}}=\frac{\dot{\mathrm{K}}(\mathrm{t})}{\mathrm{K}(\mathrm{t})}+\frac{\dot{\mathrm{N}}_{\mathrm{K}}(\mathrm{t})}{\mathrm{N}_{\mathrm{K}}(\mathrm{t})}
$$

Equation (2) will result $\left(N_{L}(t) L\right) /\left(N_{K}(t) K(t)\right)$ increase forever. Similar with the case $\mathrm{S}<\frac{s_{K}}{\eta_{\mathrm{L}}}$, from equation (15.48) we can know that $r(t)$ cannot be constant. As a result, the BGP with purely labor-augmenting technical change also cannot exist in this case.

\footnotetext{
${ }^{1}$ School of Economics and Management, Tongji University, 1500 Siping Road, Shanghai ,P.R. China, tjldf@tongji.edu.cn.
} 
Otherwise, if scientists work on both L- and K-augmenting machines, that is, $\mathrm{S}_{\mathrm{K}}+\mathrm{S}_{\mathrm{L}}=\mathrm{S}$, and let the following condition be satisfied.

$$
\frac{\dot{\mathrm{N}}_{\mathrm{L}}(\mathrm{t})}{\mathrm{N}_{\mathrm{L}}(\mathrm{t})}=\frac{\dot{\mathrm{K}}(\mathrm{t})}{\mathrm{K}(\mathrm{t})}+\frac{\dot{\mathrm{N}}_{\mathrm{K}}(\mathrm{t})}{\mathrm{N}_{\mathrm{K}}(\mathrm{t})}
$$

Inserting $\frac{\dot{N}_{L}(t)}{N_{L}(t)}=\eta_{L} S_{L}, \frac{\dot{N}_{K}(t)}{N_{K}(t)}=\eta_{K} S_{K}$ and $\frac{\dot{K}(t)}{K(t)}=s_{K}$ into equation (3) we can otain

$$
\eta_{\mathrm{L}} \mathrm{S}_{\mathrm{L}}=\eta_{\mathrm{K}} \mathrm{S}_{\mathrm{K}}+\mathrm{s}_{\mathrm{K}}
$$

Using (4) and $S_{K}+S_{L}=S$ we can solve $S_{K}$ as given by (5).

$$
S_{K}=\frac{\eta_{L} S-s_{K}}{\eta_{L}+\eta_{K}}>0
$$

Inserting (5) in $\frac{\dot{\mathrm{N}}_{\mathrm{K}}(\mathrm{t})}{\mathrm{N}_{\mathrm{K}}(\mathrm{t})}=\eta_{\mathrm{K}} S_{\mathrm{K}}$ we obtain

$$
\frac{\dot{\mathrm{N}}_{\mathrm{K}}(\mathrm{t})}{\mathrm{N}_{\mathrm{K}}(\mathrm{t})}=\eta_{\mathrm{K}} \mathrm{S}_{\mathrm{K}}=\eta_{\mathrm{K}} \frac{\eta_{\mathrm{L}} \mathrm{S}-\mathrm{s}_{\mathrm{K}}}{\eta_{\mathrm{L}}+\eta_{\mathrm{K}}}>0
$$

However, because the capital-augmenting technology grows at the rate greater than zero, from (15.48) we still cannot get a constant interest rate $r(t)$. As a result, the proposition still does not hold.

\section{(2)some scientists are unemployed.}

If let $S_{L}=\frac{s_{K}}{\eta_{L}}, S_{K}=0$, then we will have purely labor-augmenting technical change

$$
\left\{\begin{array}{l}
\frac{\dot{\mathrm{N}}_{\mathrm{L}}(\mathrm{t})}{\mathrm{N}_{\mathrm{L}}(\mathrm{t})}=\eta_{\mathrm{L}} \mathrm{S}_{\mathrm{L}}=\mathrm{s}_{\mathrm{K}}=\frac{\dot{\mathrm{K}}(\mathrm{t})}{\mathrm{K}(\mathrm{t})}+\frac{\dot{\mathrm{N}}_{\mathrm{K}}(\mathrm{t})}{\mathrm{N}_{\mathrm{K}}(\mathrm{t})} \\
\frac{\dot{\mathrm{N}}_{\mathrm{K}}(\mathrm{t})}{\mathrm{N}_{\mathrm{K}}(\mathrm{t})}=0
\end{array}\right.
$$

However, owing to $S_{L}+S_{K}=\frac{s_{K}}{\eta_{L}}<S$, there are $S-\frac{s_{K}}{\eta_{L}}$ scientists who do not work on any machines.

But from (15.24) and (15.31) we can know that if these scientists work on L- or $\mathrm{K}$-augmenting machines, the marginal return will be

$$
\mathrm{w}_{\mathrm{S}_{\mathrm{L}}}=\eta_{\mathrm{L}} \mathrm{N}_{\mathrm{L}} \mathrm{V}_{\mathrm{L}}=\eta_{\mathrm{L}} \mathrm{N}_{\mathrm{L}} \frac{\beta \mathrm{p}_{\mathrm{L}}^{1 / \beta} \mathrm{L}}{\mathrm{r}^{*}}>0
$$

Or

$$
\mathrm{w}_{\mathrm{S}_{\mathrm{K}}}=\eta_{\mathrm{K}} \mathrm{N}_{\mathrm{K}} \mathrm{V}_{\mathrm{K}}=\eta_{\mathrm{K}} \mathrm{N}_{\mathrm{K}} \frac{\beta \mathrm{p}_{\mathrm{K}}^{1 / \beta} \mathrm{K}}{\mathrm{r}^{*}}>0
$$

When scientists work on any sector will get a marginal return greater than zero, that scientists are unemployed could not be equilibrium.

Therefore, if $S>\frac{s_{K}}{\eta_{L}}$, then the BGP with purely labor-augmenting technical change could not exist.

From the discussion above we conclude that, unless $S=\frac{s_{K}}{\eta_{L}}$, the Proposition 15.12 cannot hold.

QED. 
In order to the proposition 15.12 be held, there are two revisions as follow:

Revision 1 of Proposition 15.12 Consider the baseline model of directed technological change with the two factors corresponding to labor and capital. Suppose that the innovation possibilities frontier is given by the knowledge spillovers specification with extreme state dependence, that is, $\delta=1$, and that capital accumulates according to (15.45). Then only if $\mathbf{S}=\frac{s_{\mathrm{K}}}{\eta_{\mathrm{L}}}$, there exists a unique BGP allocation in which there is only labor-augmenting technological change, the interest rate is constant and consumption and output grow at constant rates.

Revision 2 of Proposition 15.12 Consider the baseline model of directed technological change with the two factors corresponding to labor and capital. Suppose that the innovation possibilities frontier is given by the knowledge spillovers specification with extreme state dependence, that is, $\delta=1$, and that capital accumulates according to $\dot{\mathbf{K}}(\mathbf{t})=\mathbf{Y}(\mathbf{t})-\mathbf{C}(\mathbf{t})-\delta \mathbf{K}(\mathbf{t})$. Then there exists a unique $B G P$ allocation in which there is only labor-augmenting technological change, the interest rate is constant and consumption and output grow at constant rates.

However, the revision 1 does not make sense because $S=\frac{s_{K}}{\eta_{L}}$ is an extremely restrictive requirement. The revision 2 holds and in fact it is the result of Acemoglu (2003).

But why $\dot{\mathrm{K}}(\mathrm{t})=\mathrm{Y}(\mathrm{t})-\mathrm{C}(\mathrm{t})-\delta \mathrm{K}(\mathrm{t})$ is the necessary condition to exist a unique BGP allocation in which there is only labor-augmenting technological change, the interest rate is constant and consumption and output grow at constant rates? And why the BGP will not exist if capital accumulates according to $\frac{\dot{\mathrm{K}}(\mathrm{t})}{\mathrm{K}(\mathrm{t})}=\mathrm{s}_{\mathrm{K}}>0$ ? What is the intuition of the Uzawa(1961)'s steady-state theorem?

As Acemoglu(2009,p520) pointed out that "The logic of directed technological change indicates that there are nature reasons for technology to be more labor- than capital-augmenting. While......the results are not easy to reconcile with the fact that technological change should be purely labor-augmenting (Harrod neutral)." However, we(2016) prove that only with a very small extension, the framework of directed technological change (Acemoglu,2002) could give a prediction on what determines the direction of technological progress and provide a very simple intuition for the Uzawa's steady-state theorem. According the extended framework of directed technological change, the direction of technological progress is determined by the relative size of the price elasticities of material factors and not by the change in the relative factor prices as suggested by Hicks(1932) nor by the relative size of market as indicated by Acemoglu (2002), at least on the steady-state path. Moreover, it is biased towards the factor with the relatively smaller price elasticity. Because the accumulation function $\dot{K}(t)=Y(t)-C(t)-\delta K(t)$ implies that capital accumulation with infinite elasticities of interest rate, on the steady-state equilibrium path, the natural corollary is that the capital-augmenting technological progress must be zero, and if there is technological progress, it must be purely labor-augmenting. That is also the reason why the BGP with purely labor-augmenting technological change does not exist if the capital accumulates according to $\frac{\dot{\mathrm{K}}(\mathrm{t})}{\mathrm{K}(\mathrm{t})}=\mathrm{s}_{\mathrm{K}}>0$, that is, why Proposition 15.12 does not hold, because $\frac{\dot{\mathrm{K}}(\mathrm{t})}{\mathrm{K}(\mathrm{t})}=\mathrm{s}_{\mathrm{K}}>0$ implies capital accumulation with finite elasticity. 


\section{Reference}

1. Acemoglu, Daron, 2002, "Directed Technical Change." Review of Economic Studies 69: 781-809.

2. Acemoglu, Daron, 2003, "Labor- and Capital-Augmenting Technical Change," Journal of European Economic Association, Vol.1 (1), pp. 1-37.

3. Acemoglu, Daron, 2009, Introduction to Modern Economic Growth, Princeton University Press.

4. Defu, Li and Benjamin Bental, 2016, "what determines the direction of technological progress?" working paper. 